\title{
Epidemiological profile of child victims of everyday life injuries versus road traffic accident
}

\author{
Fadoua Boughaleb $^{1,2}$, Assia Mouad ${ }^{1,2}$, Loubna Aqqaoui ${ }^{1,2,3}$, Hicham Zerhouni ${ }^{1,2}$, Fouad Ettayebi ${ }^{1,2}$ 1-2 $^{\text {and Houda }}$ \\ Oubejja $a^{1,2,3,4}$
}

1-Department of pediatric surgical emergencies, children's hospital of Rabat, Morocco

2-Faculty of medecine and pharmacy, University Mohammed V, Rabat, Morocco

3-Laboratory of Genetic and Biometry, faculty of science, university IbnTofail Kenitra, Morocco

4-Laboratory of epidemiology, clinical research and Biostatistics, faculty of medecine and pharmacy, University Mohammed V, Rabat, Morocco.

\begin{abstract}
.
Unintentional injuries (UI) correspond to "unplanned" events; they include everyday life injuries (EDL), road traffic accident (RTA) and work accidents. In our pediatric context, the latter are excluded. Aim: Draw up an epidemiological profile of UI in children hospitalized for at least 24 hours and make a comparison between EDL and RTA. Material and Methods: A cross-sectional study conducted during four years, about children hospitalized for UI, in the pediatric surgical emergency department (PSE) of the children's hospital of Rabat, Morocco. Sociodemographic and medical data were analyzed by statistical software (JAMOVI). Results: 545 files were retained. EDL represented $81.9 \%$ with a male predominance $(70.4 \%)$. The median age was 8 years $[4 ; 12]$ with predominance of school children (63.5\%). Infants predominated in EDL (15.1\%). Spring has a predominance in RTA (33\%), while there is a reversal of the trend for the other seasons $(\mathrm{p}<0.05)$. As regards the accident, the majority occurred on weekdays. The injured body parts were multiple for the RTA $(39.1 \%)$ and affected the limbs $(58.5 \%)$ for the EDL $(p<0.05)$. Radiological abnormalities were found in $79.6 \%$ of cases in EDL. The 24-hour hospital stay was for EDL (66.7\%) while RTA is hospitalized beyond 48 hours $(53.7 \%)$.
\end{abstract}

keywords: everyday life injuries; road traffic accident; hospitalization; comparison; epidemiology

\section{1- Introduction}

Unintentional Injury is defined as damage caused to a person due to an acute transfer of Energy for which there is no predetermined intent. Unintentional injuries (UIs) are a growing global public health concern in almost all countries. Children are more vulnerable to UIs due to their curiosity to experiment and explore their surroundings, coupled with an inability to understand or perceive danger $[1,2]$. Children are also at risk of worse injury due to their smaller size and physiological immaturity. In addition, the burden of injury is greater among children since they have more years ahead of them to be affected by disability [1].

Throughout the developed world, child unintentional injury is a leading cause of death [3]. However, it is important to recognize that unintentional injury encompasses a range of injury types occurring in a number of settings [3]. Most childhood accidents include traffic accidents, falls, burns, drownings, poisonings, and intoxications [4]. Ranging from temporary physical incapacity to more severe and permanent sequelae, or even death [5]. Certain injury events, such as road traffic accidents and house fires, potentially expose those involved to psychological trauma. Some families report increased emotional and financial stress following injury to a child. Severe injuries in children can result in considerable loss of schooling [6].

According to the World Health Organization (WHO), about 6 million people die of trauma worldwide each year. It is estimated that of these, 830.000 deaths and 50 million sequelae are aged from 0 to 14 years and over $90 \%$ of deaths occur in developing countries [7].

Despite higher rates of injury-related mortality among children, there is little policy focus on the subject in low and middle-income countries. The lack of recognition of the magnitude of the problem is reflected in the poor availability and monitoring of data, and the dearth of effective prevention strategies to reduce injury mortality 


\section{Objective}

The aim of this study is to compare the epidemiological characteristics of everyday life injuries versus road traffic accidents among children admitted at Children's hospital of Rabat, Morocco.

\section{2- Material and methods}

\section{2-1 Study and duration}

A cross-sectional and descriptive study was conducted between January $1^{\text {st }} 2016$ and December $31^{\text {st }} 2019$ in the pediatric surgical emergencies (PSE) department, children's hospital of Rabat, Morocco.

\section{2-2 Population}

We included all the patients less than 16 years, who presented unintentional injuries, resulting in a hospitalization. Trauma related to poisoning, intoxication and drowning were excluded because treated in another department.

Verbal and informed consent was obtained from at least one of the parents.

\section{2-3 Data}

The data were collected from PSE register, crosschecked with the hospitalization register, using a questionnaire covering the demographic, socioeconomic and injury characteristics. The cause of trauma was divided into two groups: Road traffic accident (RTA) and everyday life injuries (EDL).

The patients were divided into groups according to their lesions. Head trauma was defined as a trauma at the head, resulting in vomiting, and loss of consciousness or convulsion. Polytrauma is defined as a patient with two or more injuries, one of them being potentially life threatening. We also stratified the patients by age groups: 0 to 2 years, $>2$ to 6 years, $>6$ to 12 years and Up to 12 years.

\section{2-4 Statistical analysis}

Data were analyzed using statistical software JAMOVI. 1.6.23. The Chi-square test was used to compare variables between the two groups: Everyday life accident (EDL) and Road traffic accident (RTA).

\section{3- Results}

During the study period, 545 children with unintentional injuries were admitted at the Pediatric Surgical Emergencies Department, Children's Hospital of Rabat, Morocco. In 66,8\% cases (306 patients), the accident resulted in hospitalization for at least 24 hours. The median age was 8 years $[4 ; 12]$ with predominance of children aged more than 6 years $(63,5 \%)$. Injuries were frequently sustained at home (46.4\%), especially on weekdays $(73 \%)$. The commonest circumstances of injury were falls $(68 \%)$, followed by collision (19.6\%). Some general characteristics are shown on table 1.

Table 1: General characteristics of children victims of unintentional injuries, PSE department, children's hospital of Rabat, Morocco

\begin{tabular}{|c|c|c|}
\hline General characteristics & $n(545)$ & $\%$ \\
\hline \multicolumn{3}{|l|}{ Age group } \\
\hline $0-2$ years & 70 & 13.6 \\
\hline$>2-6$ years & 118 & 22.9 \\
\hline$>6$ years & 328 & 63,5 \\
\hline \multicolumn{3}{|l|}{ Cause of trauma } \\
\hline Everyday life (EDL) & 439 & 81.9 \\
\hline Road traffic accident (RTA) & 97 & 18.1 \\
\hline \multicolumn{3}{|l|}{ Time of occurrence } \\
\hline Sunday & 85 & 16 \\
\hline Monday & 81 & 15 \\
\hline Tuesday & 90 & 17 \\
\hline Wednesday & 76 & 14 \\
\hline Thursday & 58 & 11 \\
\hline Friday & 86 & 16 \\
\hline Saturday & 60 & 11 \\
\hline \multicolumn{3}{|l|}{ Hospitalization } \\
\hline Yes & 306 & 66.8 \\
\hline No & 152 & 33.2 \\
\hline \multicolumn{3}{|l|}{ Duration of hospital stay } \\
\hline 24 hours & 142 & 60.7 \\
\hline 48 hours and more & 92 & 39,9 \\
\hline \multicolumn{3}{|l|}{ Wards } \\
\hline PSE department & 238 & 96 \\
\hline Intensive care unit & 10 & 4 \\
\hline
\end{tabular}

The causes of UI were represented by everyday life injuries (EDL) $(81.9 \%)$ and road traffic injuries $(18.1 \%)$. As shown in Table 2, the median age was 8 years in the EDL and 9 years in RTA, the interquartiles range were $[3.5 ; 2,12]$ and $[5.75 ; 11.4]$ respectively. Furthermore, more than a half of patients was more than 6 years of age for both groups (Figure 1). The male predominance was obviously present between the two groups but not statistically significant $(\mathrm{p}=0.370)$.

The proportion of unintentional injuries was not significantly different between children from urban and rural areas $(\mathrm{p}=0.788)$.

Most injuries occurred during spring for RTA, contrary to EDL where they occurred in summer and winter with a statistically significant difference $(\mathrm{p}<0.05)$, and mostly during weekdays for both causes (Figure 2).

The Table 3 shows that the lesions included multiple injuries and polytrauma, suffered by $39.1 \%$ for children 
victims of RTA, followed by head trauma (31.5\%), while the most frequent lesion for EDL was limb fracture by $58.5 \%$ ( $p<0.001)$. The Radiological abnormalities were found in the majority of cases (79.6\% in EDL versus $73.5 \%$ in RTA).

Around $66.7 \%$ of patients were admitted at the PSE department for at least 24 hours for children victims of EDL, while $53.7 \%$ of children victims of RTA were hospitalized for more than 48 hours. Surgery was performed in the majority of cases (55.1\%) in EDL.

Table 2: Demographic characteristics of children victims of EDL and RTA, PSE department, children's hospital of Rabat, Morocco.

\begin{tabular}{|c|c|c|c|c|c|}
\hline Characteristics & $\begin{array}{l}\text { EDL } \\
(439)\end{array}$ & $\%$ & $\begin{array}{c}\text { RTA } \\
(\mathbf{9 7})\end{array}$ & $\%$ & $\mathbf{P}$ \\
\hline Median age & \multicolumn{2}{|c|}{$\begin{array}{c}8 \text { years } \\
{[3.52 ; 12]}\end{array}$} & \multicolumn{2}{|c|}{$\begin{array}{c}9 \text { years } \\
{[5.75 ; 11.4]}\end{array}$} & $<0,001$ \\
\hline Gender & & & & & 0.370 \\
\hline Girls & 133 & 30.4 & 25 & 25.5 & \\
\hline Boys & 305 & 69.6 & 72 & 74.2 & \\
\hline Age group & & & & & 0.067 \\
\hline $0-2$ years & 63 & 15.1 & 6 & 6.6 & \\
\hline$>2-6$ years & 94 & 22.6 & 20 & 22.0 & \\
\hline$>6-12$ years & 159 & 38.2 & 46 & 50.5 & \\
\hline$>12$ years & 100 & 24.0 & 19 & 23.5 & \\
\hline Urbain/ Rural & & & & & 0.788 \\
\hline Urbain & 348 & 85.7 & 77 & 84.6 & \\
\hline Rural & 58 & 14.4 & 14 & 15.4 & \\
\hline Days & & & & & 0.725 \\
\hline Sunday & 69 & 15.7 & 16 & 16.5 & \\
\hline Monday & 67 & 15.3 & 14 & 14.4 & \\
\hline Tuesday & 73 & 16.6 & 17 & 17.5 & \\
\hline Wednesday & 61 & 13.9 & 15 & 15.5 & \\
\hline Thursday & 45 & 10.3 & 13 & 13.4 & \\
\hline Friday & 70 & 15.9 & 16 & 16.5 & \\
\hline Saturday & 54 & 12.3 & 6 & 6.2 & \\
\hline Seasons & & & & & 0.009 \\
\hline Spring & 110 & 25.1 & 32 & 33.0 & \\
\hline Summer & 127 & 28.9 & 13 & 13.4 & \\
\hline Autumn & 76 & 17.3 & 24 & 24.7 & \\
\hline Winter & 126 & 28.7 & 28 & 28.9 & \\
\hline
\end{tabular}

Table 3: Clinical characteristics of children victims of EDL and RTA, PSE department, children's hospital of Rabat, Morocco

\begin{tabular}{|c|c|c|c|c|c|}
\hline Characteristics & $\begin{array}{l}\text { EDL } \\
(439)\end{array}$ & $\%$ & $\begin{array}{c}\text { RTA } \\
\text { (97) }\end{array}$ & $\%$ & $\mathbf{P}$ \\
\hline Injuries & & & & & $<0,001$ \\
\hline Head trauma & 126 & 29,9 & 29 & 31,5 & \\
\hline Limb fracture & 247 & 58,5 & 23 & 25 & \\
\hline $\begin{array}{l}\text { Thoracoabdominal } \\
\text { injuries }\end{array}$ & 6 & 1,4 & 4 & 4,3 & \\
\hline Multiple & 27 & 6,4 & 6 & 6,5 & \\
\hline Polytrauma & 16 & 3,8 & 30 & 32,6 & \\
\hline Paraclinical tests & & & & & $<0,001$ \\
\hline X-ray & 210 & 54,3 & 20 & 23,3 & \\
\hline Head CT & 93 & 24 & 22 & 25,6 & \\
\hline Body CT & 38 & 9,8 & 18 & 20,9 & \\
\hline Multiple & 31 & 8 & 26 & 30,2 & \\
\hline Biology & 15 & 3,9 & 0 & 3,2 & \\
\hline $\begin{array}{l}\text { Radiological } \\
\text { anomalies }\end{array}$ & & & & & 0,223 \\
\hline No & 76 & 20,4 & 22 & 26,5 & \\
\hline Yes & 296 & 79,6 & 61 & 73,5 & \\
\hline Hospitalization & & & & & $<0,001$ \\
\hline No & 141 & 38,5 & 10 & 11,4 & \\
\hline Yes & 225 & 61,5 & 78 & 88,6 & \\
\hline $\begin{array}{l}\text { Duration of } \\
\text { Hospital stay }\end{array}$ & & & & & $\mathbf{0 , 0 0 7}$ \\
\hline$\leq 24$ hours & 110 & 66,7 & 31 & 46,3 & \\
\hline $48-72$ hours & 28 & 17 & 23 & 34,3 & \\
\hline$>72$ hours & 27 & 16,4 & 13 & 19,4 & \\
\hline $\begin{array}{l}\text { Surgical } \\
\text { intervention }\end{array}$ & & & & & 0.008 \\
\hline No & 88 & 44,9 & 30 & 66,7 & \\
\hline Yes & 108 & 55,1 & 15 & 33,3 & \\
\hline
\end{tabular}




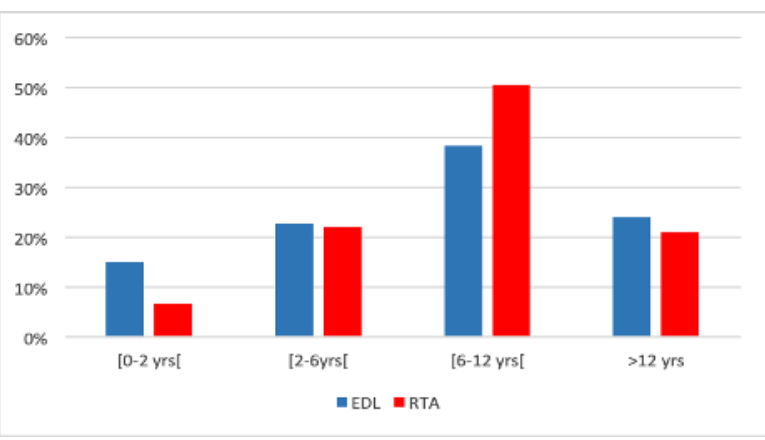

Figure 1: Distribution of children according to the cause and the age group, PSE department, children's hospital of Rabat, Morocco.

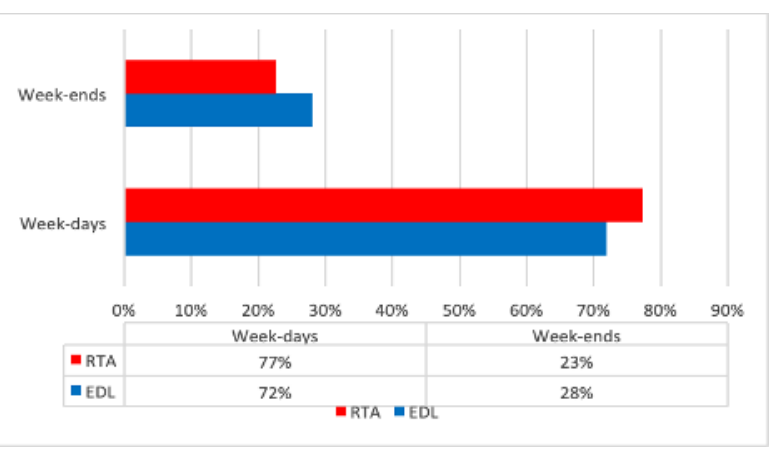

Figure 2: Distribution of children according to the cause and the weekdays, PSE department, children's hospital of Rabat, Morocco.

\section{4- Discussion:}

Unintentional injuries are a major cause of mortality and morbidity among children (up to 18 years) across the globe and contributes to over 875,000 deaths annually. This is equivalent to the deaths caused by measles, diphtheria and polio added together [7, 24].

Childhood accidents result from an interaction between genetic, behavioral, and environmental factors, as well as parental characteristics [11,12]. A number of predictable demographic and socioeconomic status are significant factors related to UI vulnerability. The WHO and UNICEF data reveal the higher UI mortality in low and middle income countries and show that boys are more vulnerable to most forms of UIs in all age groups, which is in concordance with the present study and several studies across the globe [8-10,13-20]. This can be explained by the fact that male children take more risks and are more impulsive than girls [21]. Also, culturally, boys are given relatively greater freedom to explore their environment $[6,14]$.

Our study found that accidents of everyday life are more common than the road traffic accidents. These findings are in concordance with those verified by other authors in Queensland [22], Geneva [7] and
North Kelara [18]. Besides this, Patel. et al. [23] reported that the road traffic accidents account for the majority of injuries in Great Britain, especially pedestrians.

Injury patterns are age-related. For this study infant and younger children are more vulnerable to EDL injuries, while older children show vulnerability to road traffic injuries. Children above the age of 6 years are vulnerable to all forms of UI due to their level of mobility and increased exposure to the environment.

Nirgude et al. [26] studied a wider age group (0-18 y) of children in Andhra Pradesh and reported a higher injury rate (307 per 1000 person-years). In 1962, Gordon et al. reported a morbidity of 126.6 per 1000 person-years in the $0-14 \mathrm{y}$ age group [27]. This striking difference in the morbidity rate may be attributed to the fact that he included injuries causing disability for a day or more, whereas in index study, all injuries excluding trivial ones were included. A report to UNICEF on the Vietnam multi-center injury survey revealed an overall non fatal injury rate of 48.18 per 1000 person-years, which is much lower than index finding [28].

Childhood Unintentional Injury Surveillance estimated that nearly $50 \%$ of children under 12 years suffered from unintentional injuries severe enough to warrant presentation to an emergency room (ER) and had some form of disability [7]. Rivara et al. reported that in the USA, children treated in the ER were more likely to miss school and stay in bed for two or more days, compared to children treated in clinics. More than half of the children $(55.9 \%)$ had some limitation of activity for 2 days or more.

The impact of the injury also varied depending on the etiology of the injury and child's age [25]. As in our study, the gravity of the injuries is associated to the lenght of hospital stay which is longer in RTA than in EDL. This can be explained by the violence of the trauma's mechanism in road traffic accident.

\section{5- Conclusion}

Unintentional injuries are not simply accidents but events that in many cases can be prevented with a better understanding of their cause and appropriate interventional strategies.

\section{6- References}

1- SN. Bartlett. The problem of children's injuries in low-income countries: a review. Health Policy Plan 2002;17:1-13.

2- A. Nath; VA. Naik. Profi le of Accidents in Children Less than Five years of Age belonging to a rural community in Belgaum District. Indian J Community Med 2007;32:133-4. 
3- T. Dowswell; EM. Towner; G. Simpson et al. Preventing childhood unintentional injuries-what works? A literature review. Injury Prevention 1996;2:140-149.

4- A. Hyder; D. Sugerman; S. Ameratunga; J. Callaghan. Falls among children in the developing world: a gap in child health burdenestimations? Acta Paediatr. 2007;96:1394---8.

5- RMC. Gikas; C. Schvartsman; C. Fontana. Promoc,ão da seguranc, ainfantil. In: Issler H, Leone C, Marcondes E, editors. Pediatriana atenc,ão primária. São Paulo: Sarvier; 2002. p. 130---40.

6- MC. Watson; G. Errington. (2016). Preventing unintentional injuries in children: successful approaches. Paediatrics and Child Health, 26(5), 194199. doi:10.1016/j.paed.2015.12.006

7- M. Peden; K. Oyegbite; J. Ozanne-Smith; AA. Hyder. C. Branche; AKMF. Rahman; F. Rivara; K.Bartolomeos; editors. World report on child injury prevention. Geneva: World Health Organization; 2008. WHO Guidelines Approved by the Guidelines Review Committee. PMID: 26269872.

8- H. Oubeja; N. Nekkal; H. Zerhouni; S. Belamalem; A. Haimer; M. Erraji, F. Ettayebi; A. Soulaymani. (2015). Aspects épidémiologiques des enfants traumatisés de la voie publique et hospitalisé à l'hôpital d'enfant de Rabat, de la région Rabat Salé Zemmour Zaer [Epidemiological aspects of traumatized children of the public road and hospitalized to hospital children's in Rabat, the region Rabat Salé Zemmour zaer ]. International Journal of Innovation and Applied Studies ISSN 2028-9324. 12. 769775. Innovative Space of Scientific Research Journals http://www.ijias.issr-journals.org/

9- L. A. Del Ciampo, I. R. L. Del Ciampo. Uninentional Injuries Among Children: An Observational Study in a Basic Health Unit in Ribeirão Preto, Brazil. American Journal of Pediatrics. Vol. 2, No. 5, 2016, pp. 19-22. doi: 10.11648/j.ajp.20160205.11

10- R.Barcelos ; I. Santos ; A. Matijasevich ; A. Barros ; F. Barros ; G. Franca et al. Acidentes por quedas, cortes e queimaduras emcrianc, as de 0-4 anos: coorte de nascimentos de Pelotas de 2004.Cad Saude Publica. 2017;33:e00139115.

11- R. Lyons; A. John; S. Jones; A. Johansen; A. Kemp; S. Lannon et al. Modification of the home environment for the reduction of injuries. Cochrane Database Syst Rev. 2006;4:CD003600.

12- D. Schwebel; J. Hodgens; S.Sterling. How mothers parent theirchildren with behavior disorders: implications for unintentionalinjury risk. J Safety Res. 2006;37:167---73.

13- B. Gerbaka ; et al. Prévention des accidents de la voie publique chez l'enfant au Liban. Y a-til une voie à suivre ? Arch Pédiatr 1999;6 Suppl 2 : 315-6.

14- WHO. World Report on Child Injury Prevention: Summary. Geneva: World Health Organisation, 2008. http://whqlibdoc.who.int/ publications/2008/9789241563574 _eng.pdf

15- SCV. Abib; et al. Unintentional pediatric injuries in São Paulo. How often is it severe? Acta Cir Bras. 2017;32(7):587-598. DOI: http://dx.doi.org/10.1590/s0102865020170070000010.

16- N. Atak; et al. Unintentional Injury Frequency Among Children Under Five in Malatya. The Turkish Journal of Pediatrics 2010; 52: 285 293.https://www.researchgate.net/publication/ $\underline{45706184}$

17- L.R. Inbaraj; A. Rose; K. George; et al. Incidence and Impact of Unintentional Childhood Injuries: A Community Based Study in Rural South India. Indian J Pediatr 84, 206-210 (2017). https://doi.org/10.1007/s12098-016-2260-6

18- A. Sheriff; A. Rahim; M P Lailabi; J Gopi. Unintentional injuries among children admitted in a tertiary care hospital in North Kerala. Indian J Public Health 2011;55:125-7. DOI: 10.4103/0019-557X.85248.

19- R. Seah ; R.P. Lystad ; K. Curtis ; et al. Socioeconomic variation in injury hospitalisations in Australian children $\leq 16$ years: a 10 -year populationbased cohort study. BMC Public Health 18, 1336 (2018). https://doi.org/10.1186/s12889018-6242-7.

20- H. Huang ; B.Li B ; Y. Chen ; et al. Etiology and risk factors for childhood unintentional injuries: a retrospective analysis of data at a pediatric intensive care unit. Zhongguo Dang dai er ke za zhi $=$ Chinese Journal of Contemporary Pediatrics. 2019 Apr;21(4):323-326. DOI: 10.7499/j.issn.10088830.2019.04.004.

21- F. Rebecca; F. Antony. Reducing unintentional injuries in childhood: a research review. NCB research Centre [internet]. 2010. Available at: http://www.ncb.org.uk/media/432942/childho od_unintentional_injuries_review.pdf. 
22- C. M. Cox; J. A. Kenardy, PhD; J. K. Hendrikz. A Randomized Controlled Trial of a Web-Based Early Intervention for Children and their Parents Following Unintentional Injury, Journal of Pediatric Psychology, Volume 35, Issue 6, July 2010, Pages 581592, https://doi.org/10.1093/jpepsy/jsp095.

23- D.Patel. et al. Prevention of unintentional injury in children. Paediatrics and Child Health

http://dx.doi.org/10.1016/j.paed.2017.05.004

24- GC. Patton; C. Coffey; SM. Sawyer. et al. Global patterns of mortality in young people: a systematic analysis of population health data. Lancet. 2009;374:881-92.

25- FP. Rivara; N. Calonge; RS. Thompson. Population based study of unintentional injury and impact on childhood. Am J Public Health. 1989;79:990-4.

26- Nirgude AS, Naik PR, Sheikh N. Study pattern of childhood injuries in a rural area of South India. Indian J Forensic Med Toxicol. 2010;8:62-7.

27- Gordon JE, Gulati PV, Wyon JB. Traumatic accidents in rural tropical regions: an epidemiological field study in Punjab. India Am J Med Sci. 1962;243:382-402.

28- Report to UNICEF onVietnamMulticentre injury survey [internet]. 2003. Available at: http://www.tasc-gcipf.org/downloads/

Vietnam $\% 20-\% 20$

UNICEFfinalVMISreportfinal.pdf. Accessed on 31 Oct 2013. 